\title{
22. TEXTURAL CHARACTERISTICS OF CENOZOIC PREGLACIAL AND GLACIAL SEDIMENTS AT SITE 270, ROSS SEA, ANTARCTICA
}

\author{
Peter J. Barrett, Victoria University of Wellington, New Zealand
}

\begin{abstract}
The Deep Sea Drilling Project's Site 270 was located to pass through the oldest part of a planed-off gently dipping sedimentary sequence in the south central Ross Sea, and successfully penetrated calc-silicate gneiss basement at $\mathbf{4 1 2}$ meters subbottom. The upper 20 meters (Unit 1) is largely sand-silt-clay of Gauss age, with pebbles scattered throughout. It is capped with a 20 -cm-thick veneer of diatom silty clay of Bruhnes age. Unit 2 comprises 364 meters of silty claystone with sparsely scattered pebbles, $16-25 \mathrm{~m} . y$. in age on the basis of magnetic reversal stratigraphy. Units 3 and 4 are moderately sorted sandstones totalling 2 meters in thickness, and are in sharp contact with the glacial sediments above and a fossil soil developed on 26 meters of sedimentary breccia beneath. The breccia rests on basement gneiss.

The older carbonaceous sandstone (Unit 4) is fine-grained and moderately sorted and is believed to be an estuarine deposit. The younger glauconitic sandstone is similar in texture and is a shallow marine sediment. The contact with the overlying glacial sequence is sharp, but a K-Ar age of $26 \mathrm{~m} . \mathrm{y}$. on the glauconite indicates that there is no significant time break.

The texture of the sediments of Units 1 and 2 is very similar to that of continental tills from Ohio, showing that the glacial marine sediments at Site 270 have been eroded and transported by ice with little or no modification to their size distribution. The size distribution in some samples, however, shows a slight bimodality, with broad modes in the fine sand-coarse silt and in the clay grades. Samples of this type are associated with faintly stratified parts of the sequence, and it is believed that both bimodality and the stratification are the result of size sorting due to low intensity traction or bottom currents. Therefore, the several alternations of unstratified and faintly stratified lithological units in Unit 2 are interpreted as changes in current regime, though the cause of the changes is not known. The consistently poor sorting shows that the sea floor was never above wave base $(60-70 \mathrm{~m})$ throughout the deposition of Units 1 and 2. Long-term changes in pebble abundance and parallel variations in percent of coarse sand seem independent of bedding features, and are attributed to erosional processes in the source region.

Data from Sites 270, 271, and 272 show that sedimentation was more or less continuous and relatively rapid $(40 \mathrm{~m} / \mathrm{m} . \mathrm{y}$.) from 25 to about 5 m.y. ago, when erosion truncated the sequence. Since then there has been only one interval, the Gauss magnetic epoch, with a similar sedimentation rate. The high sedimentation rate is believed to indicate a time of dominantly wet-base glaciation in Antarctica, with alpine glaciers calving directly into the Ross Embayment, whereas periods of erosion and very slow sedimentation, as in early Pliocene and late Quaternary times, are regarded as the result of dominantly dry-base glaciation on the continent with an extensive ice shelf in the Ross Embayment.
\end{abstract}

\section{INTRODUCTION}

The purpose of this paper is to report and interpret the grain size characteristics of Cenozoic preglacial and glacial marine sediments from the Deep Sea Drilling Project's Site 270, in the Ross Sea, Antarctica (Figure 1).
Sediment size distribution provides important criteria for separating unmodified ice-deposited sediments from those transported or modified by wind and water. Furthermore, variation in grain size in marine glacial sequences has been used to indicate fluctuations of glaciation on surrounding continental areas (Connolly 


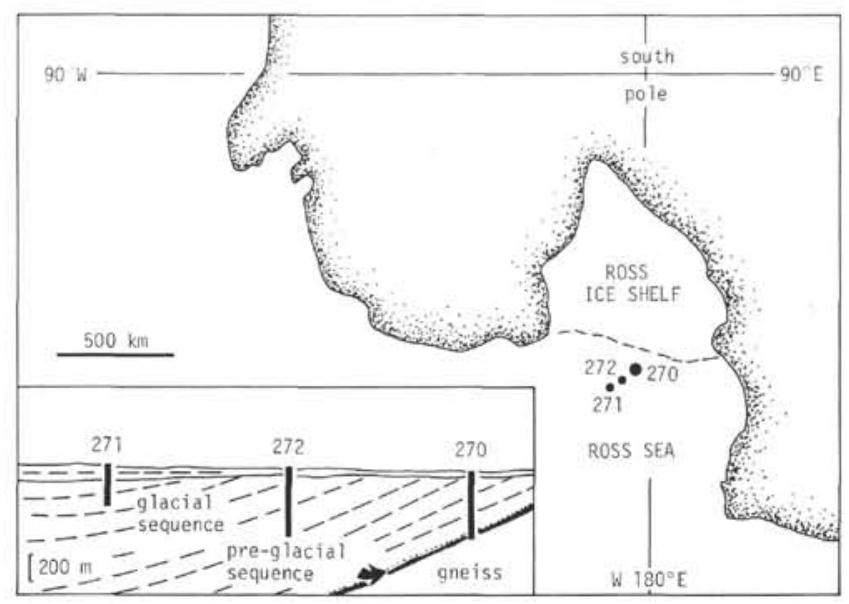

Figure 1. The Ross Sea region of Antarctica, with inset showing a cross-section of the sedimentary sequence near Site 270.

and Ewing, 1965; Kent et al., 1971). The Ross Sea cores were therefore expected to provide a record of the sedimentary processes and climatic changes in the region through the Cenozoic.

Seismic profiling in the Ross Sea had revealed a 1500meter-thick sequence of northeast-dipping sediments underlain by basement and planed off, probably by an ice sheet (Houtz and Davey, 1973). We hoped to core the entire thickness by drilling several holes, but only Site 270 , located to pass through the oldest sediment, had good recovery $(62 \%)$. We cored through 384 meters of marine glacial sediment and 28 meters of preglacial sediment to penetrate basement at 412 meters below bottom (Chapter 8, this volume). Subsequently, Sites 271 and 272 were drilled in the upper and middle parts of the sequence, respectively (Figure 1), but both were terminated prematurely for safety and technical reasons, leaving gaps in the sequence of 100 to 200 meters. This, together with the low recovery from these sites ( $7 \%$ and $37 \%$ ), resulted in a concentration of effort on Site 270.

\section{SEDIMENTARY SEQUENCE AT SITE 270}

Site 270 is in the south central Ross Sea, $400 \mathrm{~km}$ from the nearest land, with a water depth of 633 meters. The basement is calc-silicate gneiss (Unit 6, Figure 2; Chapter 8 , this volume) and is correlated with the early Paleozoic Koettlitz Marble in south Victoria Land. The 28 meters above the gneiss contain no indication of erosion or deposition by ice (e.g., striated surfaces, lonestones), and are here termed preglacial. Most of the interval is sedimentary breccia (Unit 5) with blocks up to $50 \mathrm{~cm}$ across, largely of the gneiss. A residual clay soil in the upper 3 meters grades down into the breccia. The soil is in sharp contact with one meter of quartz sand (Unit 4), which has shallow-water Oligocene foraminifera. The youngest preglacial sediment is a meter of glauconitic sandstone (Unit 3), dated by the KAr method at 26.0 m.y. (McDougall, personal communication). The preglacial sequence appears to represent accumulation of talus on a rugged terrain and subsequent soil development, followed by shallow-water deposition.

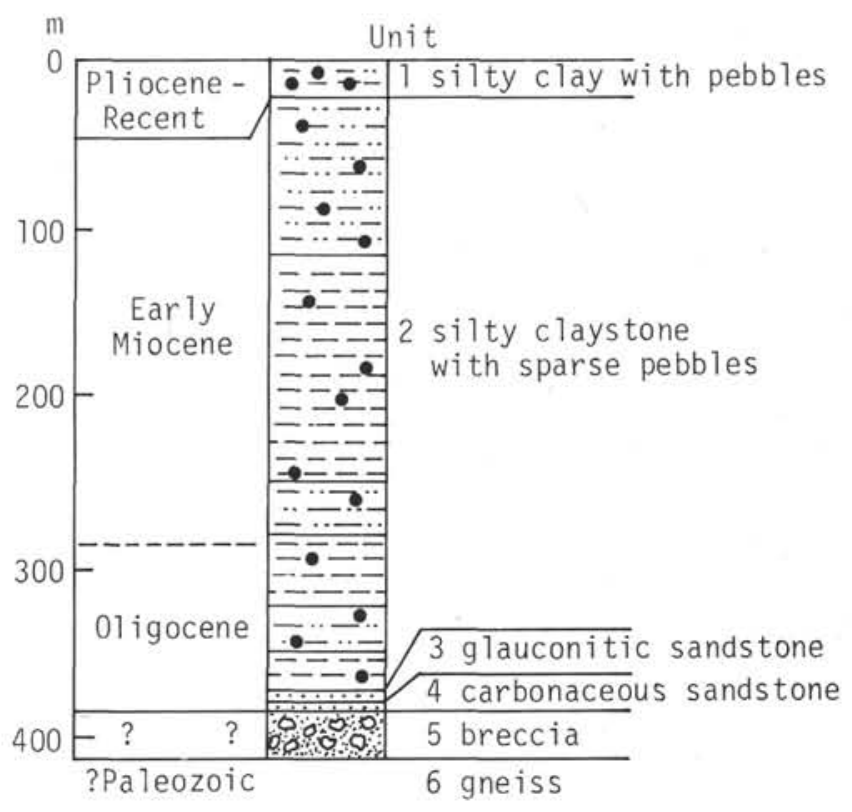

Figure 2. The stratigraphy at Site 270, south central Ross Sea.

Unit 2 is largely silty claystone. Granules and pebbles believed to be dropped from melting ice, are sparsely scattered throughout. The contact with the glauconitic sandstone is sharp. Bedding features are very subtle and are most commonly picked out by light color differences. These, and variations in clast density have been used to divide Unit 2 into 10 subunits (Figure 2; Chapter 8 , this volume). Three of the subunits have no detectable bedding features at all.

Benthonic foraminifera from the lower two thirds of the unit show that the age ranges down from early Miocene to the Oligocene. Paleomagnetic studies on samples from Unit 2 (Allis et al., this volume) have provided a more accurate chronology with a reversal stratigraphy for the upper 230 meters. The sedimentation rate has been more or less constant at $41 \mathrm{~m} / \mathrm{m} . \mathrm{y}$. from 16.7 to $20.7 \mathrm{~m} . \mathrm{y}$. The age of the base of the glacial sequence by extrapolation is 25.0 or $25.5 \mathrm{~m}$.y., consistent with the minimum age of 26.0 m.y. from the glauconite (above).

The upper 20 meters at Site 270 is almost entirely pebbly sand-silt-clay of Gauss age (2.4-3.4 m.y.). The contact with the silty claystone of Unit 2 was not seen, but is inferred to be the unconformity seen on profiler records. The break represents the removal of at least several hundred meters of glacial marine sediments after the area was tilted to the northeast. The top $20 \mathrm{~cm}$ of Core 1 is a diatom silty clay with some sand but no pebbles. The diatoms indicate a Bruhnes age $(<0.69$ m.y.). These two distinct subunits illustrate further Fillon's thesis (1972) that a substantial disconformity separates relatively coarse Gauss sediments from finegrain Bruhnes sediments in the Ross Sea.

\section{METHODS}

Grain size distributions were determined for 30 samples by standard sieving and pipetting procedures, 
and from measurements of pebbles in the core face as it was being described at Site 270 .

\section{Clasts}

We attempted to measure the size and mark the position of each clast $2 \mathrm{~mm}$ or more in length. Even with two sedimentologists describing and measuring, the pressure to reduce the backlog of unprocessed coree became excessive, and for two intervals we recorded only clasts more than $4 \mathrm{~mm}$ across. The apparent long axis is used as an estimate of pebble size largely because the clast distribution can most easily be seen in the flat surface of the split core. In addition, Friedman (1958) has shown empirically that the mean of apparent long axes of quartz grains in a thin section is an only slightly biased estimate of the mean size determined by sieving.

$$
\mathrm{M}_{\text {thin section }}=0.90 \mathrm{M}_{\text {sieving }}+0.38 \phi
$$

Chief sources of error in determining the number of pebbles per meter for the standard core width are in measurement (measurements were made quickly and to the nearest $\mathrm{mm}$ ), in not recognizing and registering a clast, and in poor preservation of the core, which reduces the area over which pebbles can be seen and measured. The latter is probably the greatest source of error and may in places decrease the calculated values by as much as 20\%. An accidental duplication in describing one core section showed that operator error is small (Table 1). Therefore, differences of more than $20 \%$ in the number of pebbles per meter are believed to reflect real differences in most cores.

TABLE 1

Numbers of Pebbles Measured for Section 12-1, Site 270

\begin{tabular}{lccc}
\hline Operator & $\begin{array}{c}\text { Larger than } \\
2 \mathrm{~mm}\end{array}$ & $\begin{array}{c}\text { Larger than } \\
4 \mathrm{~mm}\end{array}$ & $\begin{array}{c}\text { Larger than } \\
8 \mathrm{~mm}\end{array}$ \\
\hline Barrett & 19 & 5 & - \\
Ford & 18 & 4 & - \\
\hline
\end{tabular}

\section{Sand, Silt, Clay}

Twenty-seven samples of 10 to $20 \mathrm{~g}$ were taken from the glacial sequence for size analysis. The 23 samples from Unit 2 were selected to represent the different facies and to cover the stratigraphic interval more or less evenly. Three samples from the two preglacial sandstone units were analyzed. After disaggregation, each sample was washed through a $4 \phi(0.063 \mathrm{~mm})$ screen. The sand fraction was sieved into $0.5 \phi$ classes on a Ro-tap shaker, with the time set at five minutes because of the small screen loadings (rarely more than $1 \mathrm{~g}$ of sand on a $20-\mathrm{cm}$ screen). The size distribution of the fine fraction was determined by pipetting for $1 \phi$ intervals down to $8 \phi$ $(0.004 \mathrm{~mm})$.

Disaggregation proved difficult for the samples from Unit 2, all were semilithified or lithified. Each sample was crushed gently between two wooden blocks so that the matrix passed through a $2-\mathrm{mm}$ sieve. Sodium ox- alate, a deflocculant, and water were added; the sample was boiled for ten minutes and wet-sieved. If the sand fraction appeared to contain aggregates the process was repeated. Microscopic examination after sieving showed that a few samples still contained more than $10 \%$ aggregates in the finer grades. These are marked in Appendix 1, where the raw data are presented. The estimated weight of aggregates was subtracted before the frequency percent was calculated.

Pipetting revealed a recurrent strong mode in the coarse silt grade, suggesting that the fine fraction might not be fully disaggregated. Two previously processed samples were subjected to ultrasonic treatment in a bath for two hours, and then for another two hours. A pipette analysis was carried out after each run. The results (Figure 3) show that in both cases the ultrasonic treatment disaggregated about $20 \%$ of the silt fraction, but that a further two-hour treatment made a difference of less than $2 \%$. The data also show a satisfactory level of precision for the method. Within-sample variation is shown in Figure 4 by the separate analyses run on adjacent pieces of Sample 33-2, $20 \mathrm{~cm}$. Size data in Appendix I are from samples rerun after $2 \mathrm{hr}$ ultrasonic treatment to insure complete disaggregation.

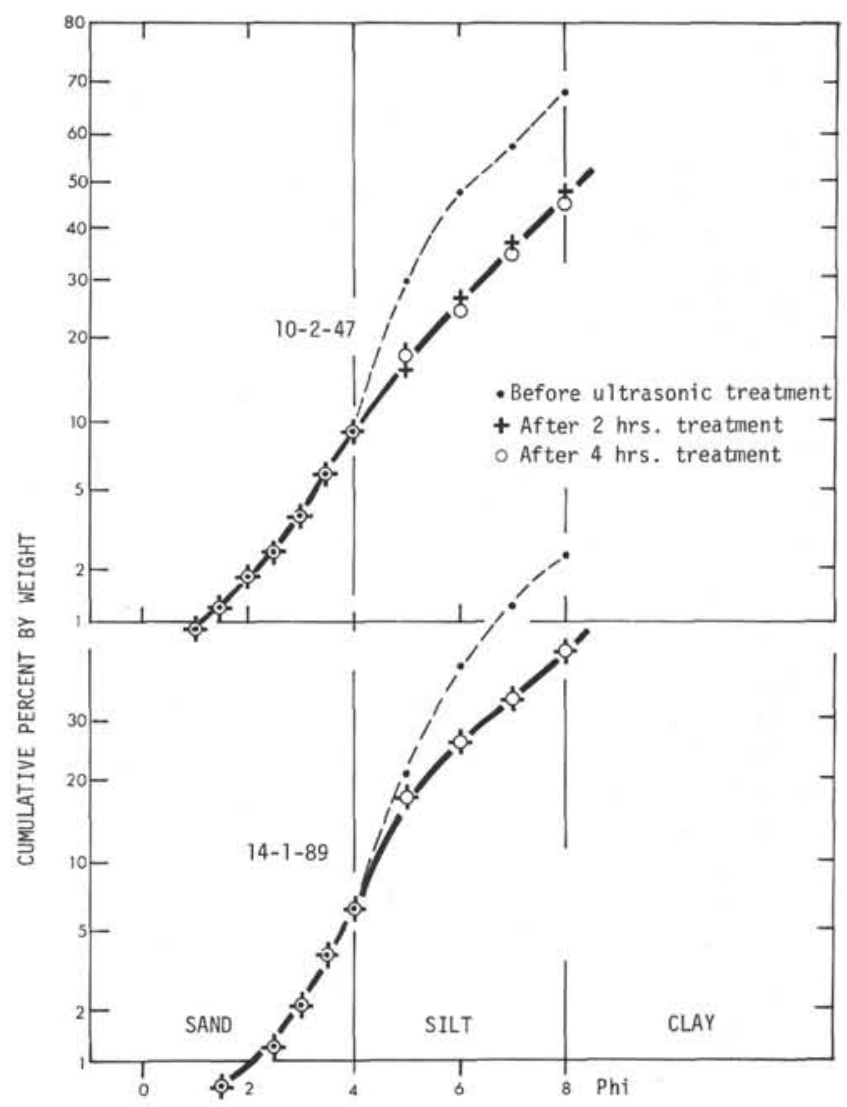

Figure 3. Comparison of grain-size distributions for silty claystone before and after ultrasonic treatment. The sample is completely disaggregated after $2 \mathrm{hr}$., and further treatment has not artificially increased the grain size. 


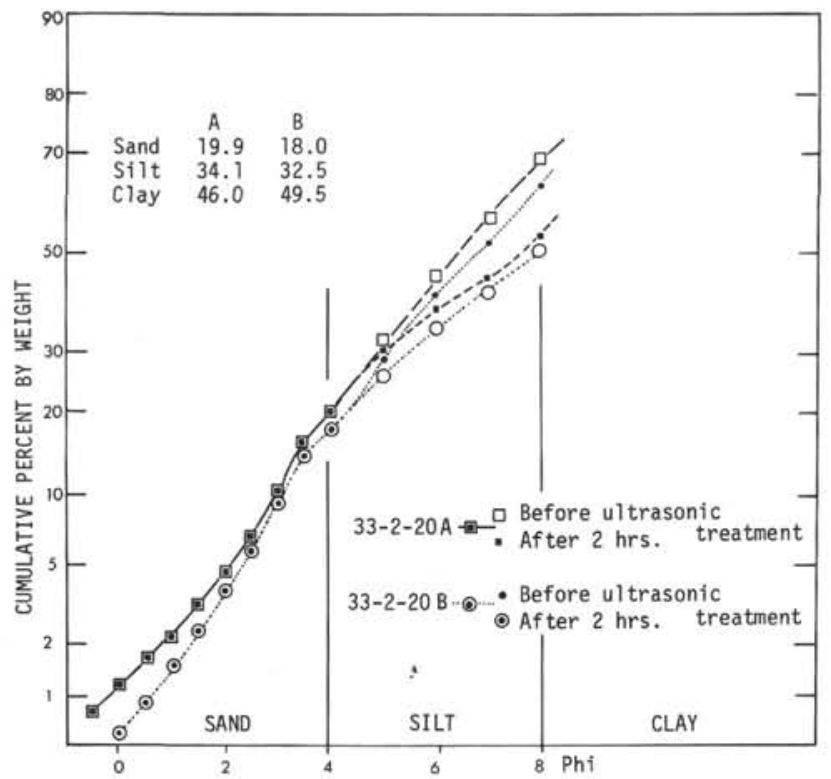

Figure 4. Comparison of grain-size distributions from adjacent core samples, that is, taken within a 5-cm interval, before and after ultrasonic treatment. The difference is small but appears signigicant compared with the even smaller differences in repeat runs after ultrasonic treatment.

\section{PREGLACIAL SEDIMENTS}

All three samples analyzed consist of a dominant sand fraction clearly separated from a subordinate fine fraction (Figure 5). The sand fraction of Sample 44-1, 132 $\mathrm{cm}$ has two closely spaced modes at $2 \phi$ and $3 \phi$, a feature attributed to the variation in grain size of the fine laminae in the core. In contrast, Sample $44-1,144 \mathrm{~cm}$ has a single mode in the sand fraction and its lower standard deviation $(1.0 \phi)$ is believed to be more typical of the unit. Sample $43-6,124 \mathrm{~cm}$ has about $15 \%$ glauconite whose average grain size is finer than those of the quartz and feldspar. This has also resulted in a bimodal sand fraction (Figure 5).

The grain-size distributions of the three samples are typical of water-sorted sediments deposited in environments of moderate energy, such as alluvial or tidal channels onshore, or offshore on the continental shelf. The foraminifera in Unit 4 indicate very shallow water, possibly a littoral environment, and the common carbonaceous material also suggests a coastal situation. However, the sorting is too poor for beach sand; deposition in an estuary seems most likely.

The high proportion of glauconite in Sample 43-6, 124 $\mathrm{cm}$ indicates marine shelf sedimentation at a time of low sediment influx (Cloud, 1955). The size distribution is similar to that of modern nearshore sediments off the east coast of New Zealand (Lewis, 1973), where Lewis' sand facies ( $\overline{\mathrm{X}}=2.0 \phi$ to $3.2 \phi ; \sigma=0.3 \phi$ to $1.1 \phi$ ) extends out from the coast only four $\mathrm{km}$. Beyond this, and in water depths of more than 30 meters, the sediment becomes much finer grained. Unit 3 probably accumulated in a similar shallow-water, nearshore situation.

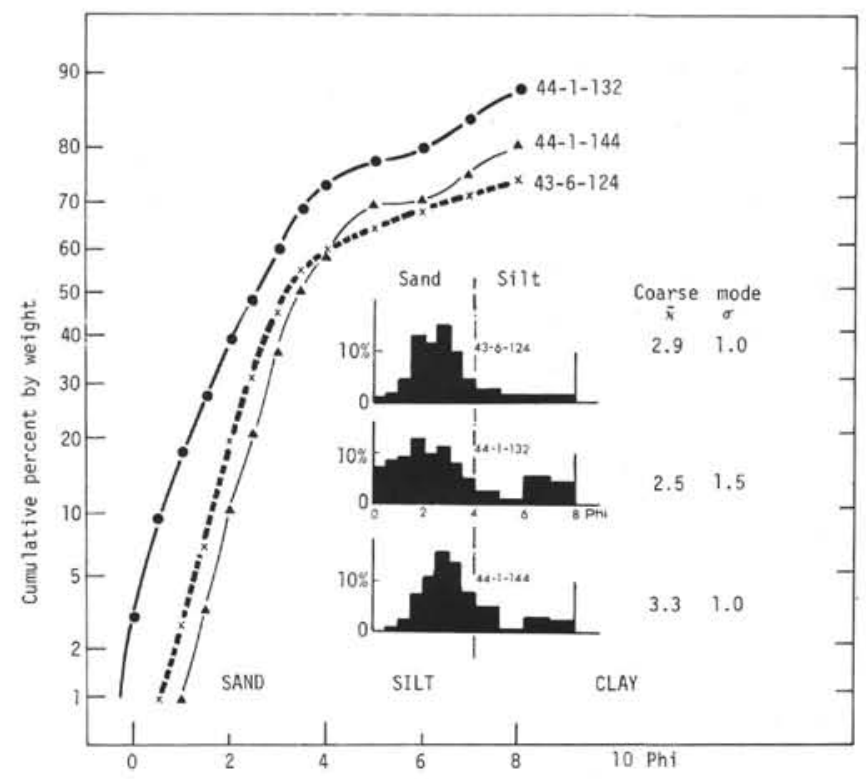

Figure 5. Grain size distribution for shallow water sandstone samples from beneath the glacial sequence at Site 270 .

The fossil soil at the top of Unit 5, the estuarine sand of Unit 4, and the nearshore marine sand of Unit 3 are therefore believed to represent a series of relative rises in sea level, which, according to fossil evidence, continued into the glacial sequence.

\section{GLACIAL SEDIMENTS}

\section{Grain Size Analysis}

Almost all of the samples from Unit 2 are silty claystones; those from Unit 1 are sand-silt-clay. For fine-grain sediments like these, the C-M plots of Passega (1957) which compare the 1 percentile (C) with the median grain size $(\mathrm{M})$ provide perhaps the best means of showing the average size and degree of sorting. Plots of the common statistical measures (mean, standard deviation, skewness, kurtosis) and their derivatives, are appropriate only for sediments for which at least $80 \%$ of the distribution can be determined. This was not feasible for any samples analyzed from the glacial sequence.

Passega used C-M plots (Figure 6) to identify sediments affected by various depositional processes. He found that sediments deposited or reworked by traction currents fell in a field close to the line $\mathrm{C}=\mathrm{M}$ because of their high degree of sorting. The position and grouping in the field depended on the level and variation in current intensity. In contrast, sediments deposited from suspension are poorly sorted and occupy a subcircular field some distance from the line. Turbidity current sediments occupy elongate fields parallel to the line $\mathrm{C}=\mathrm{M}$, the distance from the line being greater for currents with denser suspensions. Bull (1962) has since found that mudflow debris plots as an elongate field parallel to $\mathrm{C}=\mathrm{M}$. It is similar to the field for turbidity current deposits, but is much further from the line, indicating deposition from a denser suspension.

The glacial sediments from Unit 2 (Figure 6) form a circular field far from the line $\mathrm{C}=\mathrm{M}$. The closest com- 

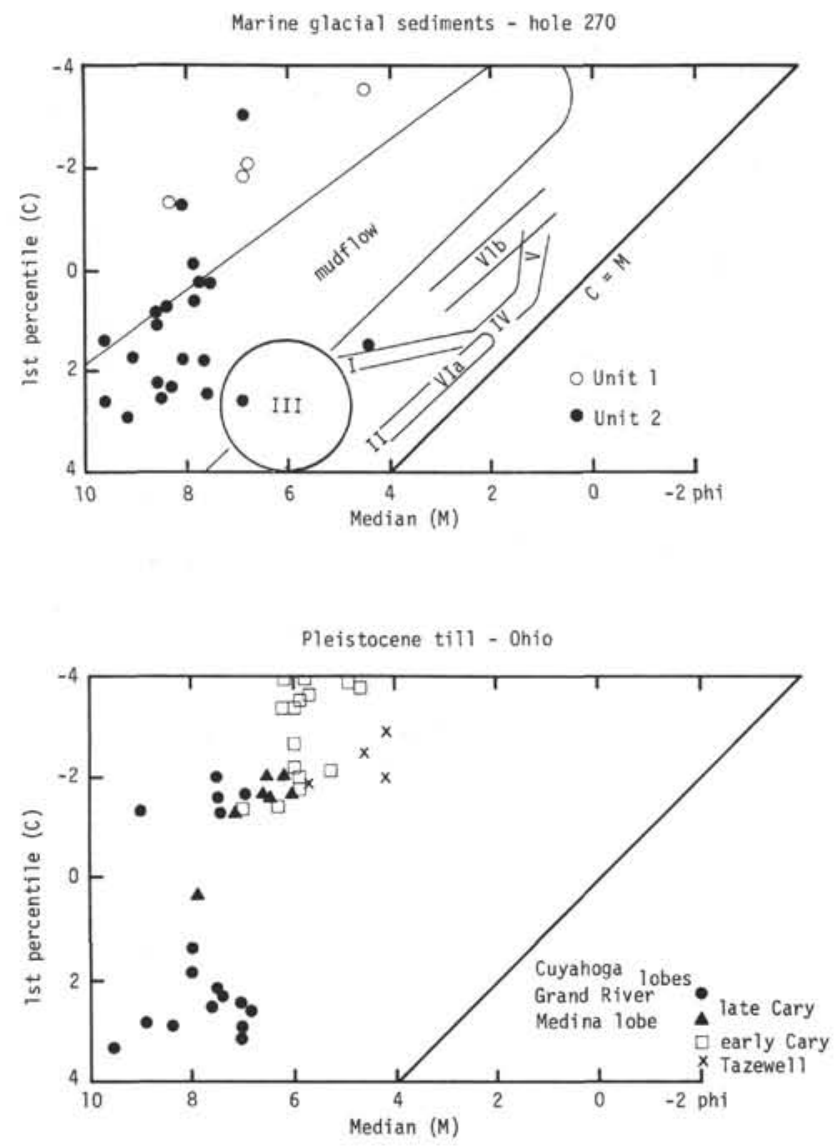

Figure 6. $C-M$ (1 percentile vs. median) plots for samples from the glacial sequence at Site 270. Some late Pleistocene tills from Ohio are plotted separately for comparison. The patterns defined by Passega (1957) for more common sediments represent: $I=$ low-intensity traction currents; II = low-density turbidity currents; III = settling from suspension; $I V=$ moderate-intensity traction currents; $V=$ high-intensity traction currents; VIa, $b=$ moderate- to high-density turbidity currents. The mudflow field is from Bull (1962).

parison seems to be with some of the late Pleistocene tills of northeastern Ohio (Shepps, 1953). The samples from Unit 2 define a field similar to till samples from the clay-rich late Cary till, while those coarser samples from Unit 1, which plot even further from the line, are in the same field as the older and more sandy tills. This comparison suggests that the glacial sediments at Site 270 represent debris eroded by continental ice and deposited with little modification to the grain size distribution.

It is also evident that the field of Unit 2 samples overlaps the fine-grained part of the field defined by Bull's mudflow samples. However, the limited range in average grain size in Unit 2 argues against mudflows as an important means of transportation.

If the grain size distribution in individual samples is examined, several slight differences point to subtle modification of the characteristically glacial texture. Four basic types of size distribution can be seen in the histograms (Figure 7).
I. A rectangular size distribution extending over the entire range of size classes. This is confined to and typifies the Gauss-age sediments of Unit 1.

II. A rectangular size distribution in the silt range with a coarse tail extending into the sand range. Sand content varies between $6 \%$ and $13 \%$ and clay content between $44 \%$ and $55 \%$.

III. A bimodal size distribution with a clearly developed mode in the very fine sand or coarse silt grade. For the finer mode only the coarse tail extends into the silt range. Clay content ranges between $42 \%$ and $53 \%$, similar to that of Type 2 .

Types II and III include all but 3 of the samples from Unit 2 and appear to grade into each other with the development of a low point in the medium or fine silt grades.

IV. A unimodal size distribution with its coarse tail extending through the silt class. Clay content ranges from $64 \%$ to $75 \%$ and sand is $3 \%$ or less.

Types I and II are considered unmodified glacial textures because of their even size distribution, with its implied absence of sorting, and their textural similarity to continental tills. The apparent gradation of Type II to Type III samples (noted above) suggests that Type III is a modification of Type II. The modification has been most complete in Sample 40-2, $116 \mathrm{~cm}$ (Figure 7), which has a large very fine sand mode, and a very low fine silt content. The character of the size distribution and its position on the C-M plot (Figure 6) show that this sediment was reworked by low intensity traction currents before burial. It is probable then that the same sort of reworking modified the other Type III samples, but to a lesser degree.

Another argument for weak traction currents is the evidence that the process involved the entrainment of sediment. The grain size of the modal classes in Type III samples, very fine to coarse silt, is that which first moves as current intensity is increased (Inman, 1949). Sediments coarser and finer than this require higher current intensities, because of larger grain size on one hand, and of decreased bed roughness and increased cohesiveness on the other.

Nevertheless, sorting is poor in all but one of the samples, despite the slow-average sedimentation rate of $41 \mathrm{~m} / \mathrm{m}$.y., and the modification in size distribution is not sufficient to distinguish these sediments from the continental tills of Ohio. It is therefore assumed that the shear stress on the sea floor must have remained at or below the lower limits of sediment movement (equivalent to a mean velocity of $20 \mathrm{~cm} / \mathrm{sec}$ over the lower $\mathrm{m}$ ) during the deposition of most of Unit 2 .

Grain size modification by postdepositional processes and by currents in the water column may occur, but is probably much less important. Postdepositional processes like burrowing and intrastratal solution are unlikely because burrowing is rare in Unit 2, and because the presence of unstable minerals like hornblende and clinopyroxene show that intrastratal solution is almost nonexistent.

Currents higher in the water column, as distinct from bottom currents, are not favored as effective grain-size modifiers, either. If they were, the mode in each sample 


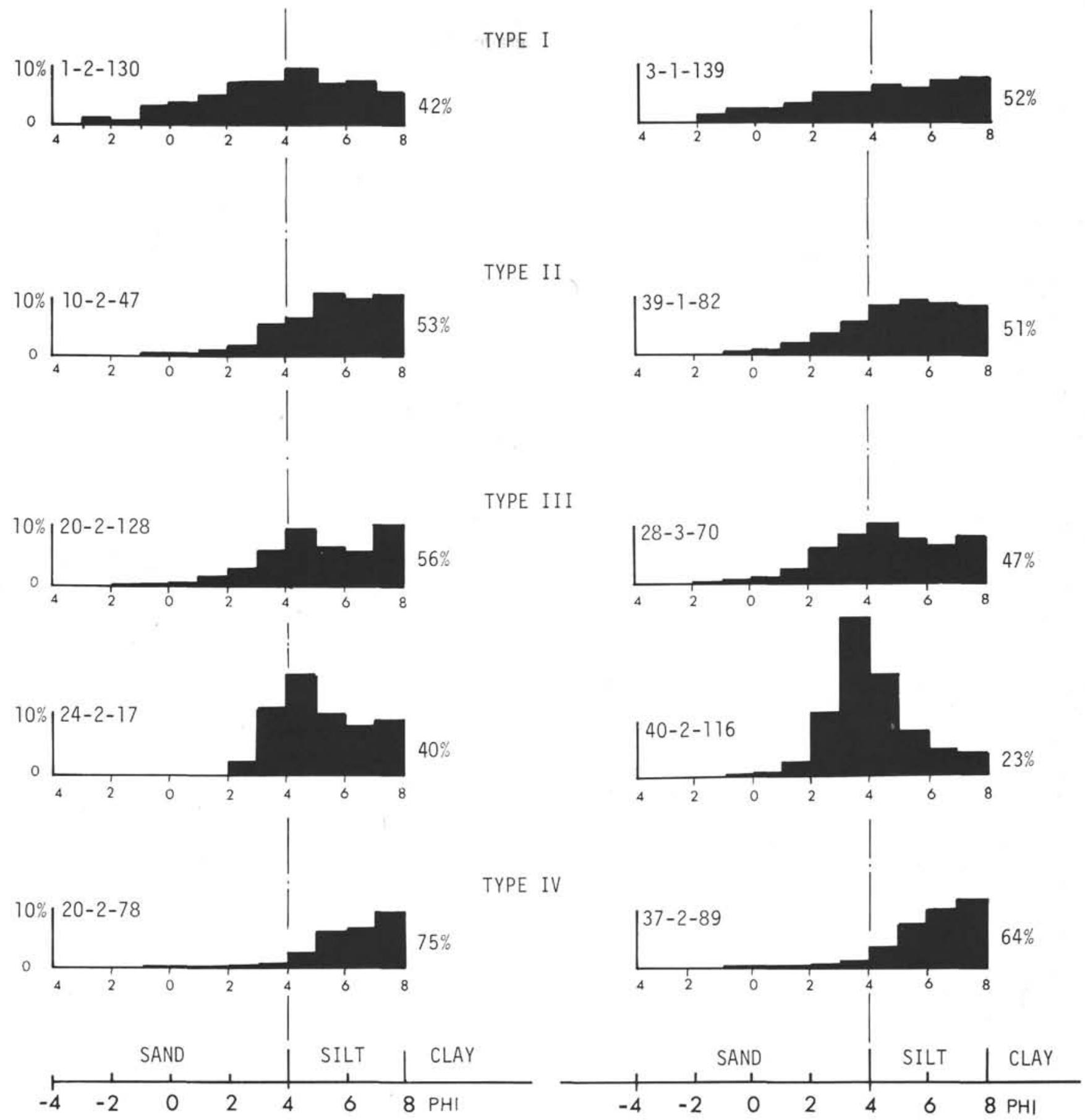

Figure 7. Histograms illustrating four basic types of grain-size distribution in the glacial sediments at Site 270. The Type I distribution is confined to the Gauss-age sediments of Unit 1; the other three are spread through Unit 2, with Type II characterizing intervals, and Type III characterizing stratified intervals.

would be a complex function of several factors, one or two of which could vary considerably in space and time; current velocity, depth of current, timing of sediment release from the ice (and whether continuous or discontinuous), and the original size distribution of the sediment in the ice. Variations in these should produce a range of modal classes, rather than the recurring modal class that is found.

The types of grain size distribution appear to be related (Table 2) to the presence or absence of the faint color stratification that has been used to subdivide Unit 2. Type III and IV size distributions are almost exclusively associated with the stratified intervals, and there is a preference of Type II sediments for unstratified intervals. This suggests that the stratification is caused directly or indirectly by size sorting due to the low-intensity traction currents that modify the size distribution, and that the unstratified intervals represent deposition when the sea floor was in no way influenced by waves or currents. 
It is possible, however, that some stratification and sorting was accomplished by sediment entrainment due to wave action, with lateral movement by weak bottom currents $(<20 \mathrm{~cm} / \mathrm{sec})$. If this is so the effect has been slight and it is clear that Site 270 has been at or below wave base $(60-70 \mathrm{~m}$, Stetson, 1939) throughout the deposition of Unit 2.

Changes in sediment texture vary stratigraphically, as well as by association with bedding characteristics. The percentage of sand coarser than $0.25 \mathrm{~mm}(2 \phi)$ which is clearly ice-rafted (Kent et al., 1971), is low in the basal 15 meters of Unit 2, is relatively high $220-360$ meters below bottom, and then drops back to near zero in the upper part of Unit 2 (Figure 8). The percentage is much higher in Unit 1 (11\% to $22 \%$ ). This stratigraphic variation is crudely reflected in the percentage of clay. The

TABLE 2

Relationship Between Size Distribution and Numbers of Samples with Each Type of Size Distribution and the Subunits in Which They Occur in Unit 2

\begin{tabular}{lllll}
\hline \multicolumn{1}{c}{ Type } & I & II & III & IV \\
\hline Stratified & - & 3 & 11 & 3 \\
Unstratified & - & $\frac{5}{8}$ & $\frac{1}{12}$ & $\frac{二}{3}$ \\
\hline
\end{tabular}

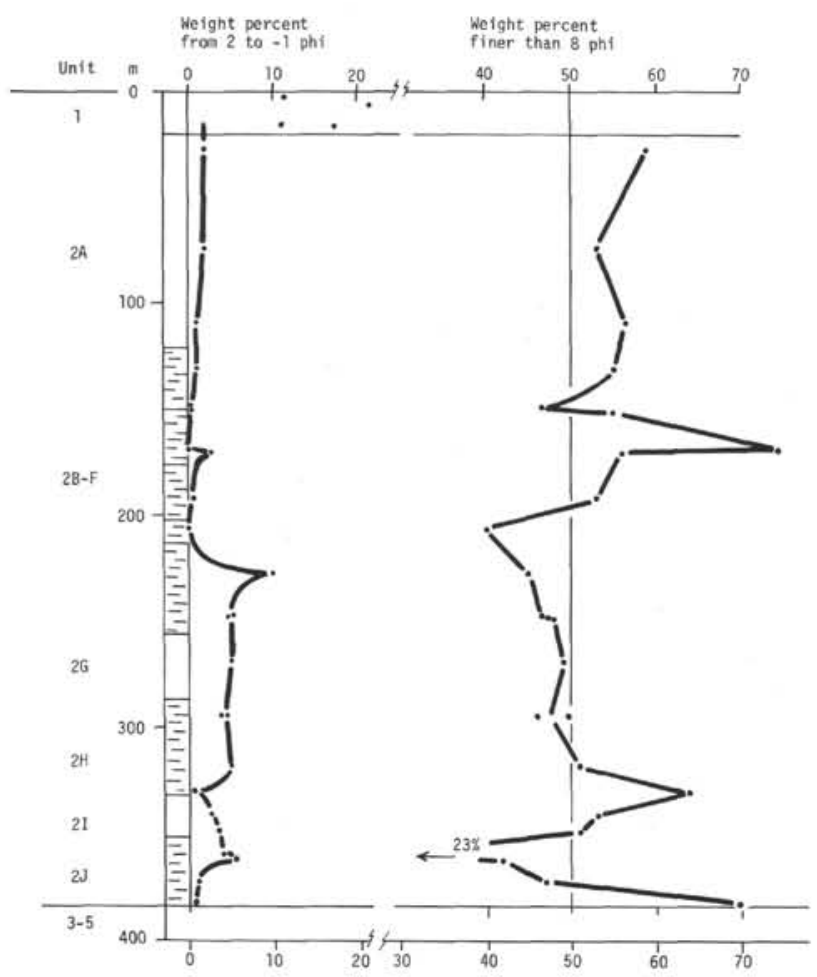

Figure 8. Stratigraphic variation in percent coarse sand $(0.25-2 \mathrm{~mm})$ and in percent clay. Dashed intervals in the stratigraphic column represent stratified units; clear intervals represent nonstratified units. number of samples is small to draw conclusions from, but it does seem that the stratigraphic trends are largely independent of the lithologic subunits based on bedding characteristics and hence indirectly on changes in local current regime. The differences in percentage sand are therefore attributed to differences in grain-size distribution of the glacial debris being transported, and not to depositional or postdepositional processes.

\section{Pebble Distribution}

The distribution of pebbles throughout the glacial sequence (expressed as number per meter of core length) is shown in Figure 9. The low pebble density required that the numbers be averaged over intervals of several meters to obtain numbers sufficient for a meaningful average. Each value therefore represents a period of between 50,000 and $250,000 \mathrm{yr}$.

Maximum pebble size, indicated by the largest long axis in each core section, seems to be significantly greater over intervals of higher coarse sand and pebble density. However, this may be due simply to the larger number of pebbles in the section increasing the likelihood of finding a longer one.

Pebble abundance varies stratigraphically in a similar way to the percent sand coarser than $0.25 \mathrm{~mm}$ (Figure 8), as von Huene et al. (1973) found at Site 176 in the Gulf of Alaska. They believed that this showed that most or all coarse sand was transported in the same way as the pebbles, by ice-rafting. They also implied that the bulk of the finer sediment is not ice-rafted, for they interpreted increases in pebble abundance (and in abundance of coarse sand) as increases in intensity of icerafting. However, at Site 270, all of the glacial marine sediments can be explained reasonably as ice-rafted continental glacial debris, for they have a virtually identical texture to the continental tills of Ohio (Figure 6). Thus, for Site 270, variations in abundance of pebbles and coarse sand are believed to represent changes in texture of the debris transported by the ice.

\section{Climatic Interpretation}

The coarse sand and pebbles throughout Unit 2, and through the cores at Sites 271 and 272, show that sediment-laden ice has been melting in the south-central Ross Sea more or less continuously from 25 to about 5 m.y. ago. The thin and incomplete sedimentary record since then indicates that glaciation of the surrounding land area has in general been more intense presumably as the mantle of ice inhibited erosion on land and consequently deposition at sea.

Warnke (1971) has argued that the efficiency of ice as an eroding agent will decrease with time as the weathered bedrock and surficial material is eroded away. This contention is not supported by the sediments at Site 270. The sedimentation rate was more or less constant at $41 \mathrm{~m} / \mathrm{m}$.y., with no significant trend in the texture of the sediments, for the first $10 \mathrm{~m} . \mathrm{y}$. of glacial sedimentation at this site. Then, as recently as 3 m.y. ago, sediments were being deposited at a minimum rate of $20 \mathrm{~m} / \mathrm{m} . \mathrm{y}$. In contrast, the sedimentation rate has dropped to less than $1 \mathrm{~m} / \mathrm{m} . \mathrm{y}$. in the last $2 \mathrm{~m} . \mathrm{y}$. These 


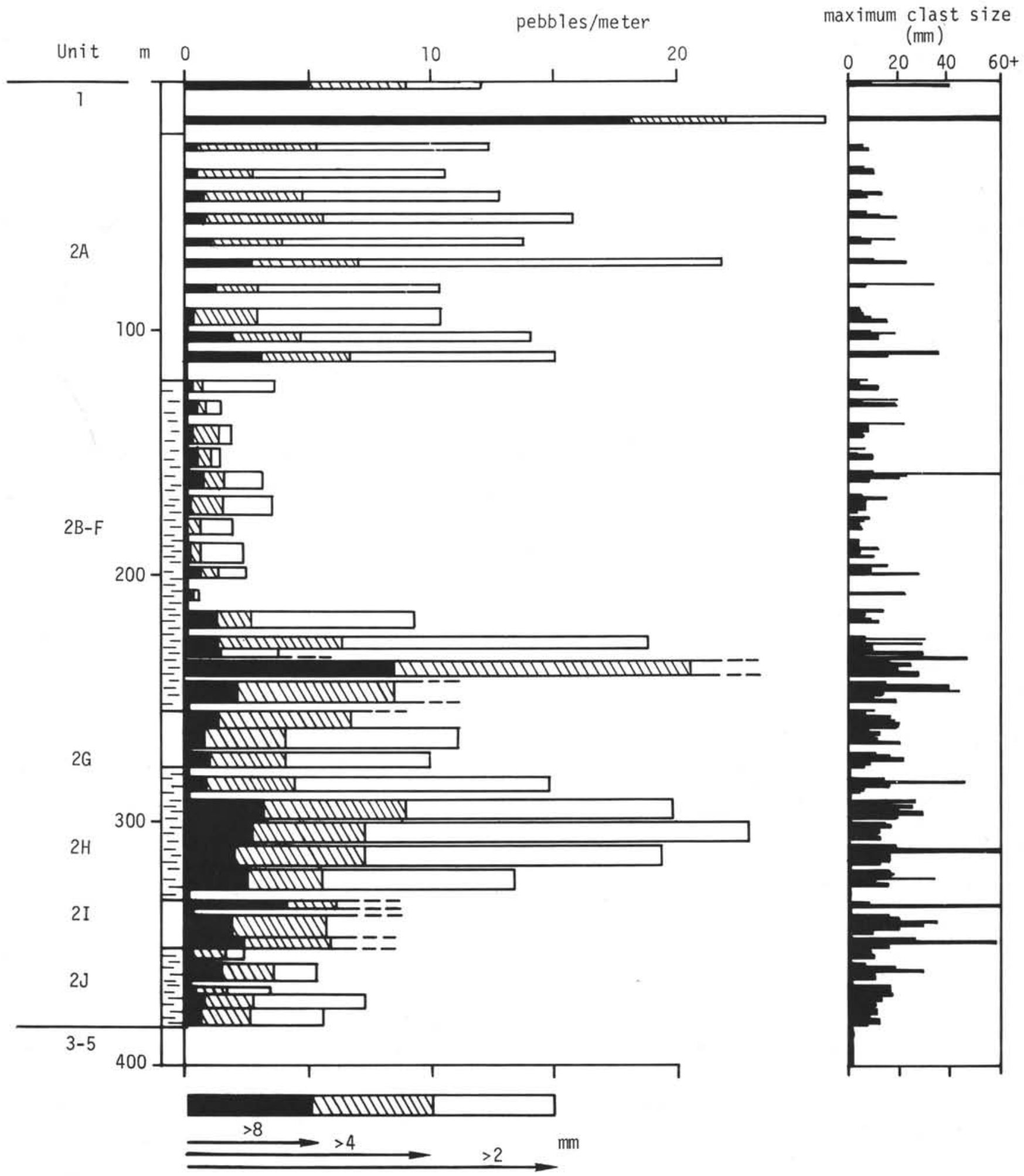

Figure 9. Stratigraphic variation in clast abundance (expressed as the number per meter of core length) and in maximum clast size (as indicated by the largest apparent long axis measurement in each $1 \frac{112}{2}$ meter of core section). Dashed intervals in the stratigraphic column represent stratified units; clear intervals represent non-stratified units. 
data suggest that the length of time over which the region was glaciated was not an important factor in determining the rate of sediment supply. It seems more likely that the rate of supply is determined by the ability of the ice to erode, and is controlled by the areal proportions of dry-base to wet-base glaciation. This latter concept was intimated by Warnke $(1968 \mathrm{a}, \mathrm{b})$ in his suggestion that a cold climate and a large ice sheet lead to less intensive, not more intensive, ice-rafting than a warmer glacial climate. Fillon (1972) provides an additional reason for reduced sedimentation in the Ross Sea during intense glaciation. Because it takes much longer for the ice to reach the front of an extended ice shelf most of the sediment melts out from the base before the ice reaches the front and calves. At times when no ice shelf exists, glaciers and ice tongues calve into the Ross embayment and the bergs move relatively quickly northward depositing sediment over the entire continental shelf. The submarine topography of the eastern Ross Sea, and the major unconformity near the base of the Pliocene (Hayes et al., 1973) has been attributed to extension and grounding of the Ross Ice Shelf, necessarily a time of intense glacierization in Antarctica. This also supports the general thesis that times of intense cold in Antarctica result locally in a reduced stratigraphic record.

The Ross Sea sequence is therefore believed to record the beginnings of temperate, probably alpine, glaciation in the region about $25 \mathrm{~m} . \mathrm{y}$. ago. Glaciation continued with little change in extent or intensity at least until 16 m.y. ago and probably until 5 m.y. ago, as deduced from similar sedimentation rates and lithologies at Sites 271 and 272.

The climate cooled substantially in the early Pliocene, when the Ross Ice Shelf formed and reached its maximum extent well northward of Site 270. Its thickness at that time was about 600 meters, compared with the present 300 meters at the front, $100 \mathrm{~km}$ to the south. The ice shelf disappeared during the Gauss magnetic epoch, and rapid glacial sedimentation from melting bergs continued much as in late Oligocene and early Miocene times. The ice shelf formed again in the Matuyama epoch and has persisted until the present.

\section{SUMMARY}

Sedimentation began at Site 270 with the accumulation of terrestrial talus. Subsequent rises in sea level through the Oligocene resulted in the deposition of thin estuarine and nearshore marine sediments. Glacial sedimentation began 25 m.y. ago without a significant time break in water depths of more than 60 meters (below wave base). The sediment was supplied by bergs from temperate glaciers and ice tongues throughout the late Oligocene and Miocene. The Ross Sea region has been much colder over the last 5 m.y., and has supported an ice shelf similar to or more extensive than that existing today, except during the Gauss magnetic epoch when glaciers and ice tongues calved directly into the Ross Embayment.

The similarity of the texture of glacial sediments at Site 270 to that of continental tills from Ohio, as shown on C-M plots, shows that the sediments have been eroded and transported by ice and deposited with little or no modification to their size distribution. Bimodality of some size distributions shows, however, that about half of the samples have experienced limited size sorting that is here attributed to low-intensity traction currents. These samples are associated with the stratified parts of the sequence, and indicate that the stratification is also the result of size sorting. Therefore the several alternations of stratified and unstratified lithologic units are interpreted as changes in current regime, though the reason for the changes is not known.

Changes in pebble density and in percentage of coarse sand seem independent of changes in bedding characteristics, and are attributed to differences in size distribution caused by erosional processes. An alternative point of view, that changes of this type must result from changes in intensity of ice-rafting (von Huene et al., 1973 ) is less likely, because all but one of the 27 samples from the glacial sequence have grain-size distributions typical of continental till.

\section{ACKNOWLEDGMENTS}

The writer is grateful to A. B. Ford, U.S. Geological Survey, Menlo Park, for helping with the core description and the tedious pebble measuring at Site 270, and to Ross Powell and Russ Plume, Geology Department, Victoria University of Wellington, for their assistance with the grain-size analyses. Financial support for laboratory work was provided by Victoria University's Internal Research Committee.

\section{REFERENCES}

Bull, W. B., 1962. Relation of textural (CM) patterns to depositional environment of alluvial fan deposits: J. Sediment. Petrol., v. 32, p. 211-216.

Cloud, P. E., 1955. Physical limits of glauconite formation: Am. Assoc. Petrol. Geol. Bull., v. 39, p. 484-492.

Connolly, J. R. and Ewing, M., 1965. Ice-rafted detritus as a climatic indicator in Antarctic deep-sea cores: Science, v. 150 , p. $1822-1824$.

Fillon, R. H., 1972. Evidence from the Ross Sea for widespread submarine erosion: Nature Phys. Sci., v. 238, p. 4042.

Friedman, G. M., 1958. Determination of sieve-size distribution from thin-section data for sedimentary petrological studies: J. Geol., v. 66, p. 394-416.

Hayes, D. E., Frakes, L. A., Barrett, P., Burns, D. A., Chin, P. -H., Ford, A. B., Kaneps, A. G., Kemp, E. A., McCollum, D. W., Piper, D. J. W., Wall, R. E., and Webb, P. N., 1973. Leg 28 deep-sea drilling in the southern ocean: Geotimes, v. 18 , p. $19-24$.

Houtz, R. and Davey, F. J., 1973. Seismic profiler and sonobuoy measurements in Ross Sea, Antarctica: J. Geophys. Res., v. 78(17), p. 3448-3468.

Inman, D. L., 1949. Sorting of sediments in the light of fluid mechanics: J. Sediment. Petrol., v. 19, p. 51-70.

Kent, D., Opdyke, N., and Ewing, M., 1971. Pattern of climate change in the North Pacific using ice-rafted detritus as a climate indicator: Geol. Soc. Am. Bull., v. 82, p. 27412754.

Lewis, K. B., 1973. Sediments on the continental shelf and slope between Napier and Castlepoint, New Zealand: New Zealand J. Marine Freshwater Res., v. 7, p. 183-208.

Passega, R., 1957. Texture as characteristic of clastic deposition: Am. Assoc. Petrol. Geol. Bull., v. 41, p. 19521984.

Shepps, V. C., 1953. Correlation of the tills of northeastern Ohio by size analysis: J. Sediment. Petrol., v. 23, p. 34-48. 
Stetson, H. C., 1939. Summary of sedimentary conditions on the continental shelf of the east coast of the United States. In Trask, P. D. (Ed.), Recent Marine Sediments-A Symposium, p. 230-244.

von Huene, R., Larson, E., and Crouch, J., 1973. Preliminary study of ice-rafted erratics as indicators of glacial advances in the Gulf of Alaska. In Kulm, L. D. and von Huene, R., et al., Initial Reports of the Deep Sea Drilling Project, Volume 18: Washington (U.S. Government Printing Office), p. 835-842.
Warnke, D. A., 1968a. Is the intensity of Antarctic glaciation recorded in marine sediments? [abs.]: Ann. Mtg., Geol. Soc. Am. Southeast Sec., p. 73.

1968b. Comments on a paper by Goodell, H. G. and Watkins, N. D., "The paleomagnetic stratigraphy of the Southern Ocean: $20^{\circ}$ West to $160^{\circ}$ East latitude": Deep-Sea Res., v. 15, p. 723-725. 1971. Glacial erosion, ice-rafting and glacial-marine sediments: Antarctica and the Southern Ocean: Am. J. Sci., v. 269 , p. $276-294$. 
APPENDIX 1

One Percentile, Median, and Cumulative Percentages (by weight) for Samples of Preglacial and Glacial Sediments from Site 270, Ross Sea

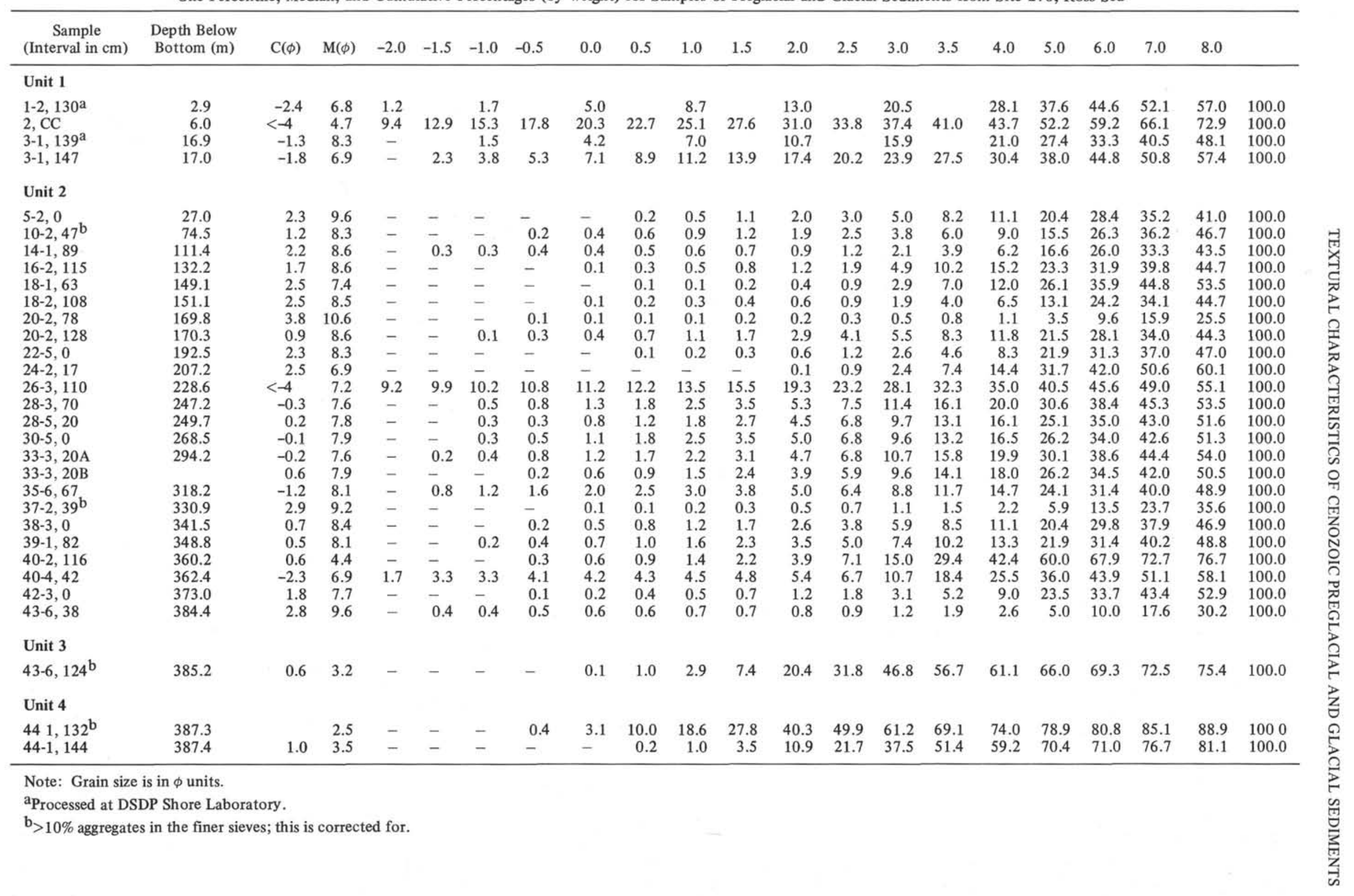

